\title{
Editorial
}

Cerebrovascular

Diseases

\section{Microvascular Lesions at the Bottom of the Brain: New Neuropathological Insights}

\author{
Andreas Charidimou ${ }^{a}$ Enikö Kovari ${ }^{b}$ \\ ${ }^{a}$ Hemorrhagic Stroke Research Program, Department of Neurology, Massachusetts General Hospital Stroke Research \\ Center, Harvard Medical School, Boston, Mass., USA; ${ }^{b}$ Department of Psychiatry, University Hospitals and Medical \\ Faculty of Geneva, Geneva, Switzerland
}

Little is known about the neuropathology and clinical relevance of small vessel disease in the cerebellum, which have somehow been neglected and understudied. This is partly reflected, for example, when vascular neurologists or stroke physicians encounter patients with spontaneous (i.e. nontraumatic) parenchymal haemorrhage in the cerebellum - determining the predominant underlying microangiopathy contributing to the bleed is not straightforward. In a rather simplistic, but practical way, sporadic small vessel disease in the brain has been traditionally categorised as either cerebral amyloid angiopathy or 'hypertensive arteriopathy' [1]. Cerebral amyloid angiopathy is a predominantly superficial pathology affecting cortical and leptomeningeal smallvessels due to amyloid- $\beta$ deposition. Hypertensive arteriopathy, an umbrella term including arteriolosclerosis, lipohyalinosis, and fibrinoid necrosis, more often affects the deep arterial perforators (e.g. lenticulostriate) supplying the basal ganglia, thalami and brainstem structures. Paralleling this distribution, it is commonly considered that strictly lobar macrobleeds or microbleeds are more likely related to cerebral amyloid angiopathy, whereas deep bleeds are associated with hypertensive arteriopathy. When it comes to the bottom of the brain, the cerebellum, a similar working hypothesis is currently missing.

Looking back at the original pathological investigations, both cerebral amyloid angiopathy and hypertensive-related damage seem to affect the cerebellum to a (c) 2015 S. Karger AG, Base

1015-9770/15/0402-0001\$39.50/0 certain extent. In his landmark paper on the pathological signatures of cerebrovascular amyloid deposition, Stefanos Pantelakis from the Geneva Brain collection, descripted small arterioles and capillaries within the cerebellar cortex affected by this pathology [2]. Similar findings were also reported in a Japanese autopsy study, which found that $14.3 \%$ of cerebellar bleeds were associated with cerebral amyloid angiopathy [3]. On the other hand, ruptured and unruptured microaneurysms (miliary aneurysms) associated with intracerebral haemorrhage and hypertension have also been found in the perforating vessels that irrigate the cerebellum (in addition to the basal ganglia, pons, and deep white matter) $[4,5]$.

In a recently published issue of Cerebrovascular Diseases, Jacques De Reuck and his colleagues reported new interesting data on microangiopathies in the cerebellum [6] - another elegant investigation in the sequel of the neuropathological/7T postmortem MRI studies performed by the group. In 104 postmortem brains of elderly subjects with various neurodegenerative and cerebrovascular pathologies, cortical cerebellar microbleeds and microinfarcts were detected on 7T MRI of horizontal sections of a cerebellar hemisphere. These microvascular lesions showed the same burden in cases with $(n=15)$ versus without $(\mathrm{n}=73)$ amyloid angiopathy. The prevalence and load of both lesions were higher only in cases with pure and mixed vascular dementia without amyloid angiopathy $(\mathrm{n}=8)$. These findings were consistent with the
Dr. Andreas Charidimou, MD, PhD 175 Cambridge Street Suite 300, Boston, MA 02114 (USA) E-Mail andreas.charidimou.09@ucl.ac.uk 
neuropathological investigation of the cerebellar hemispheres: more microbleeds and microinfarcts were observed in association with arteriosclerotic leptomeningeal vessels in vascular dementia brains [6]. Of note, the vascular dementia group had a higher prevalence of hypertension and antithrombotic drug use during life. Overall, data presented in the paper are in line with the idea of cerebellar involvement occurring less often and later in the natural history of cerebral amyloid angiopathy than in the cerebrum.

Despite the relatively small sample size of the diagnostic groups, and the potential of selection bias, inherent in any autopsy/MRI study, the paper by Jacques De Reuck et al. is an important modern step in characterising microangiopathy-related cerebellar injury. As the authors comment, these data support the idea of being cautious in attributing cerebellar microbleeds to cerebral amyloid angiopathy as another haemorrhagic manifestation of the disease, a notion currently reflected in the Boston criteria $[7,8]$. Further studies are needed to expand their findings and interpretation in cases of spontaneous cerebellar intracerebral haemorrhage [9] with intensive neuropathological investigation, and including postmortem imaging. Until then, in patients with cerebellar signs of small vessel disease (e.g. macro- or micro-bleeds), clinicians might be guided by assessing microangiopathy burden in the whole brain and associated vascular risk factors. Some clinically relevant data can also be extrapolated from other more 'pure' clinical cohorts. For example, in CADASIL, a 'pure' form of small vessel disease and vascular dementia (with affected individuals progressing to dementia at 40-60 years of age), the presence of coexistent Alzheimer's disease pathology and CAA in unlikely: microbleeds frequently occur in the cerebellum and are associated with symptomatic stroke presentation $[10,11]$.

\section{Disclosure Statement}

None declared.

\section{References}

1 Greenberg SM: Small vessels, big problems. N Engl J Med 2006;354:1451-1453.

2 Pantelakis S: [A particular type of senile angiopathy of the central nervous system: congophilic angiopathy, topography and frequency]. Monatsschr Psychiatr Neurol 1954;128: 219-256.

3 Itoh Y, Yamada M, Hayakawa M, Otomo E, Miyatake T: Cerebral amyloid angiopathy: a significant cause of cerebellar as well as lobar cerebral hemorrhage in the elderly. J Neurol Sci 1993;116:135-141.

4 Charcot JM, Bouchard C: Nouvelles recherches sur la pathogenie de l'hemorrhagie cerebrale. Arch Physiol Norm Pathol 1868;642: 110-127.

5 Cole FM, Yates P: Intracerebral microaneurysms and small cerebrovascular lesions. Brain 1967;90:759-768.
6 De Reuck JL, Deramecourt V, Auger F, Durieux N, Cordonnier C, Devos D, Defebvre L, Moreau C, Capparos-Lefebvre D, Pasquier F, Leys D, Maurage CA, Bordet R: The significance of cortical cerebellar microbleeds and microinfarcts in neurodegenerative and cerebrovascular diseases. A post-mortem 7.0-tesla magnetic resonance study with neuropathological correlates. Cerebrovasc Dis 2015;39:138-143.

7 Linn J, Halpin A, Demaerel P, Ruhland J, Giese AD, Dichgans $M$, van Buchem MA, Bruckmann H, Greenberg SM: Prevalence of superficial siderosis in patients with cerebral amyloid angiopathy. Neurology 2010;74: 1346-1350.

8 Knudsen KA, Rosand J, Karluk D, Greenberg SM: Clinical diagnosis of cerebral amyloid angiopathy: validation of the Boston criteria. Neurology 2001;56:537-539.
9 Falcone GJ, Brouwers HB, Biffi A, Anderson CD, Battey TW, Ayres AM, Vashkevich A, Schwab KM, Rost NS, Goldstein JN, Viswanathan A, Greenberg SM, Rosand J: Warfarin and statins are associated with hematoma volume in primary infratentorial intracerebral hemorrhage. Neurocrit Care 2014;21:192199.

10 Viswanathan A, Guichard JP, Gschwendtner A, Buffon F, Cumurcuic R, Boutron C, Vicaut E, Holtmannspötter M, Pachai C, Bousser MG, Dichgans M, Chabriat H: Blood pressure and haemoglobin $\mathrm{Alc}$ are associated with microhaemorrhage in CADASIL: a two-centre cohort study. Brain 2006;129:2375-2383.

11 Lee JS, Kang CH, Park SQ, Choi HA, Sim KB: Clinical significance of cerebral microbleeds locations in CADASIL with R544C NOTCH3 mutation. PLoS One 2015;10:e0118163. 